28. Reichard, H.: Serum ornithine transcarbamylase activity in normal individuals. Enzymol. Biol. Clin., 1: 47 (1961).

29. Short, E. M., Conn, O. H., Snodgrass, P. J., Campbell, A. G. M., and Rosenberg, L. E.: Evidence for X-linked dominant inheritance of ornithine transcarbamylase deficiency. N. Engl. J. Med., 288: 7 (1973).

30. Snodgrass, P. J.: The effects of $\mathrm{pH}$ on the kinetics of human liver ornithine-carbamyl phosphate transferase. Biochemistry, 7: 3047 (1968).

31. Snodgrass, P. J., and Parry, D. J.: The kinetics of serum ornithine carbamoyltransferase. J. Lab. Clin. Med., 73: 940 (1969).

32. Thaler, M. M., Hoogenraad, N. J., and Boswell, M.: Reye's syndrome due to a novel protein-tolerant variant of ornithine-transcarbamylase deficiency. Lancet ii: 438 (1974).

33. Wolfson, S. K., and Williams-Ashman, H. G.: Isocitric and 6-phosphogluconic

Copyright @ 1976 International Pediatric Research Foundation, Inc. dehydrogenase in human blood serum. Proc. Soc. Exp. Biol. Med. 96: 231 (1957).

34. Wroblewski, F., and LaDue, J. S.: Serum glutamic-pyruvic transaminase in cardiac and hepatic disease. Proc. Soc. Exp. Biol. Med., 91: 569 (1956).

35. Informed consent was obtained for this investigation and, where appropriate, for other procedures detailed in this paper.

36. Radiochemical Centre, Amersham, England.

37. This research was supported in part by the Institute for Research into Mental and Multiple Handicap.

38. Requests for reprints should be addressed to: R. J. Pollitt, Ph.D., M.R.C. Unit for Metabolic Studies in Psychiatry, Middlewood Hospital, P.O. Box 134, Sheffield, S6 ITP, England (UK).

39. Accepted for publication May 21, 1976.

Pediat. Res. 10: 923-927 (1976)

Linear growth

retardation, growth zinc deficiency

\title{
Growth Retardation and Zinc Nutrition
}

\author{
NOEL W. SOLOMONS ${ }^{(20)}$ AND ROBERT L. ROSENFIELD \\ Departments of Medicine and Pediatrics, Pritzker School of Medicine, University of Chicago, Chicago, Illinois, USA \\ ROBERT A. JACOB AND HAROLD H. SANDSTEAD \\ United States Department of Agriculture, Agricultural Research Service, Human Nutrition Laboratorl, \\ Grand Forks. North Dakota, USA
}

\section{Extract}

Based on a previous report of a zinc deficiency syndrome in children characterized by low hair zinc, anorexia, poor growth, and hypogeusia, 12 children attending a pediatric endocrinology clinic for growth retardation and judged as having short stature as a variant of normal (SVN) were evaluated as to their zinc nutriture to learn whether zinc deficiency was a contributory factor. None was found to have the above syndrome, although one child did have a hair zinc concentration below $70 \mu \mathrm{g} / \mathrm{g}$. The mean hair zinc of the SVN subjects was lower than the hair zinc of $\mathbf{4 0}$ apparently normal adolescents, $131 \pm 37 \mu \mathrm{g} / \mathrm{g}$ vs. $168 \pm 44 \mu \mathrm{g} / \mathrm{g}(\mathrm{P}<0.02)$, but there was no difference found in plasma levels of zinc or in taste acuity. In contrast, five patients with total growth arrest secondary to juvenile Crohn's disease ( $C D$ ) were found to have multiple findings consistent with zinc deficiency including low plasma zinc, low hair zinc, or hypogeusia.

\section{Speculation}

There is a relationship between the pattern of growth and zinc deficiency in man. The pattern is characterized by a plateau in growth. The short stature of children whose growth is at a normal velocity is not likely to be due to zinc deficiency.

The trace metal, zinc, has an essential role in protein and nucleic acid metabolism in growth and development (10) and in taste acuity $(5,13)$. In man, dwarfism and hypogonadism responsive to zinc have been reported from Egypt (7) and Iran (3). A major factor in the 'occurrence of the syndrome appears to be the low bioavailability of dietary zinc because of chelation by the phytate and fiber in the high extraction whole grain bread which is a major component of the diet (8). An additional factor in Iran is the practice of geophagia; in Egypt infestations with hookworm and schistosomiasis contribute. Zinc deficiency has been implicated in the growth retardation and delayed sexual maturation seen in cystic fibrosis (4), sickle cell disease (1), and Crohn's disease (14). Hambidge et al. (5) measured the concentrations of zinc in the hair of 132 adolescents and children between the ages of 4 and 17 years; of 10 children with hair levels below $70 \mu \mathrm{g} / \mathrm{g}$ (ppm), 9 had heights below the 10th percentile and 7 had a history of poor appetite. Objective evidence of impaired taste acuity was found in 5 of 6 of the children tested. After treatment, these children showed improved taste and improved appetites, and their growth failure was therefore attributed to zinc deficiency. Although growth retardation accounts for about a third of the patients referred to pediatric endocrinologists, in a majority of such patients no nutritional or pathologic causes can be found (17). The present study was conducted to learn whether there is a substantial incidence of zinc deficiency among children evaluated for short stature in pediatric clinics, and to assess the relationship of zinc nutrition to linear growth.

\section{PATIENTS, MATERIALS, AND METHODS}

Patients were selected from among new or recent registrants in the Pediatric Endocrinology Clinic of the Wyler Children's Hospital who presented with a chief complaint of short stature. Twelve patients with unexplained short stature were studied. All were below the 3rd percentile for height according to the anthropometric data of the Iowa Child Welfare Research Station and the Harvard School of Public Health. They ranged in age from 5 to 17 
years and from pre- to early pubertal (Table 1). All but one had a normal predicted adult height (constitutional growth retardation); the other had unexplained genetic short stature and a history of poor appetite. The patients were all eventually classified as having SVN after assessment of their clinical and family histories,

Table 1. Profile of patients with short stature as a variation of normal ${ }^{1}$

\begin{tabular}{|c|c|c|c|c|c|c|c|c|}
\hline $\begin{array}{c}P a- \\
\text { tient }\end{array}$ & Sex & Age & $\begin{array}{c}\text { Per- } \\
\text { centile }\end{array}$ & $\begin{array}{c}\text { Growth } \\
\text { velo- } \\
\text { city, } \\
\mathrm{cm} / \mathrm{yr}\end{array}$ & $\begin{array}{l}\text { Pu- } \\
\text { bertal } \\
\text { stage }\end{array}$ & $\begin{array}{c}\text { Plas- } \\
\text { ma } \\
\mathrm{Zn}, \\
\mu \mathrm{g} / \\
\mathrm{dl}\end{array}$ & $\begin{array}{l}\text { Hair } \\
\mathrm{Zn}, \\
\mu \mathrm{g} / \\
\mathrm{dl}\end{array}$ & $\begin{array}{l}\text { Taste } \\
\text { score }\end{array}$ \\
\hline$l$ & F & $17 \mathrm{yr} 5 \mathrm{mo}$ & $<3$ rd & 3.0 & Mid & 80 & 169 & -2 \\
\hline 2 & $\mathbf{M}$ & 12 yг $8 \mathrm{mo}$ & $<3$ rd & 3.8 & Early & N.A. & 118 & -1 \\
\hline 3 & $\mathbf{M}$ & $11 \mathrm{yr} 11 \mathrm{mo}$ & $<3$ rd & N.A. & Pre & 81 & 50 & -1 \\
\hline 4 & $\mathbf{M}$ & 10 yr $6 \mathrm{mo}$ & $<3$ rd & 4.5 & Pre & 76 & 113 & 0 \\
\hline 5 & F & 5 yr 4 mo & $<3$ rd & 4.0 & Pre & 59 & 131 & 0 \\
\hline 6 & $\mathbf{M}$ & 12 yr 9 mo & $<3$ rd & N.A. & Early & 87 & 152 & -1 \\
\hline 7 & M & 15 yr 4 mo & $<3$ rd & 4.3 & Early & 90 & 171 & 0 \\
\hline 8 & F & $10 \mathrm{yr} 11 \mathrm{mo}$ & $<3$ rd & 4.0 & Early & 84 & 92 & -1 \\
\hline 9 & $M$ & $11 \mathrm{yr} 3 \mathrm{mo}$ & $<3$ rd & 5.7 & Pre & 71 & 110 & 0 \\
\hline 10 & $\mathbf{F}$ & $12 \mathrm{yr} 11 \mathrm{mo}$ & $<3$ rd & 6.0 & Early & 57 & 138 & -5 \\
\hline 11 & $\mathbf{M}$ & 13 yr 9 mo & $<3$ rd & 4.5 & Pre & 69 & 177 & 0 \\
\hline 12 & $\mathbf{F}$ & $10 \mathrm{yr} 4 \mathrm{mo}$ & $<3$ rd & 4.5 & Early & 74 & $15^{\prime}$ & 0 \\
\hline
\end{tabular}

${ }^{1}$ N.A.: not available; pre: prepubertal; early: early puberty; mid: midpuberty.

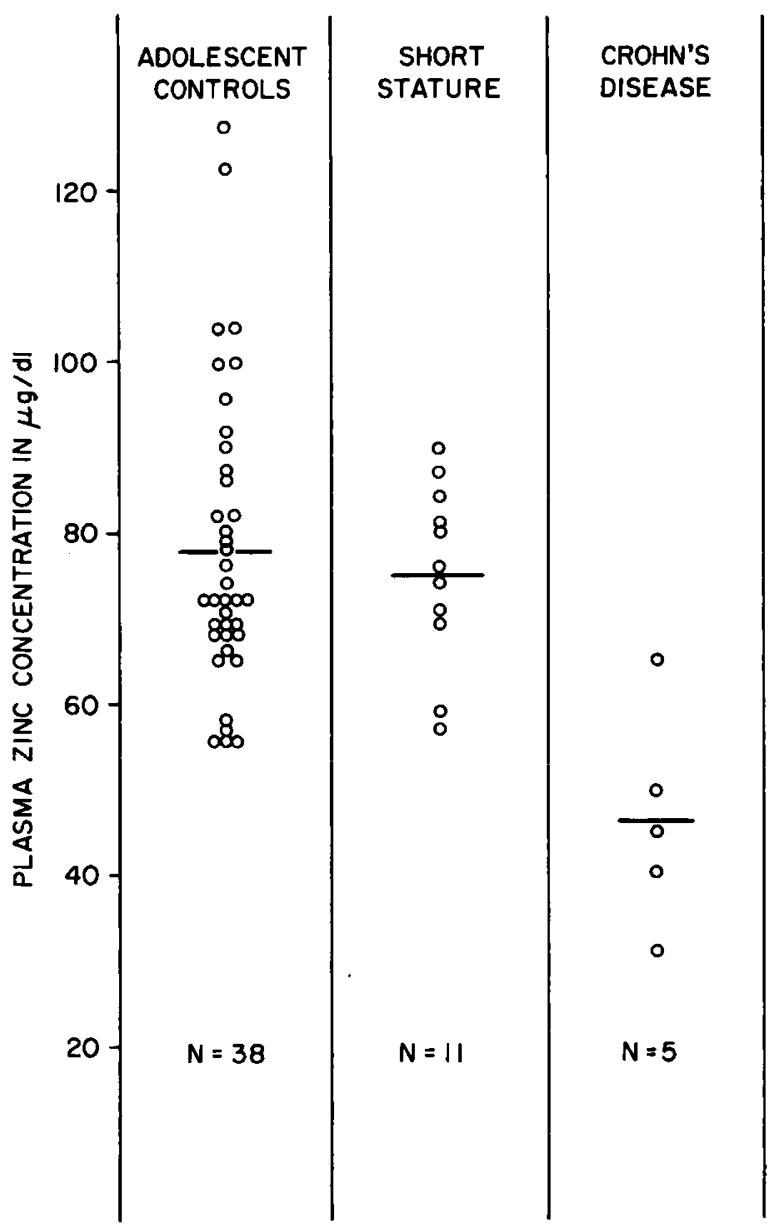

Fig. 1. Plasma zinc concentrations in adolescent control subjects, in the short stature patients as a variation of normal, and in the patients with juvenile Crohn's disease and growth arrest.

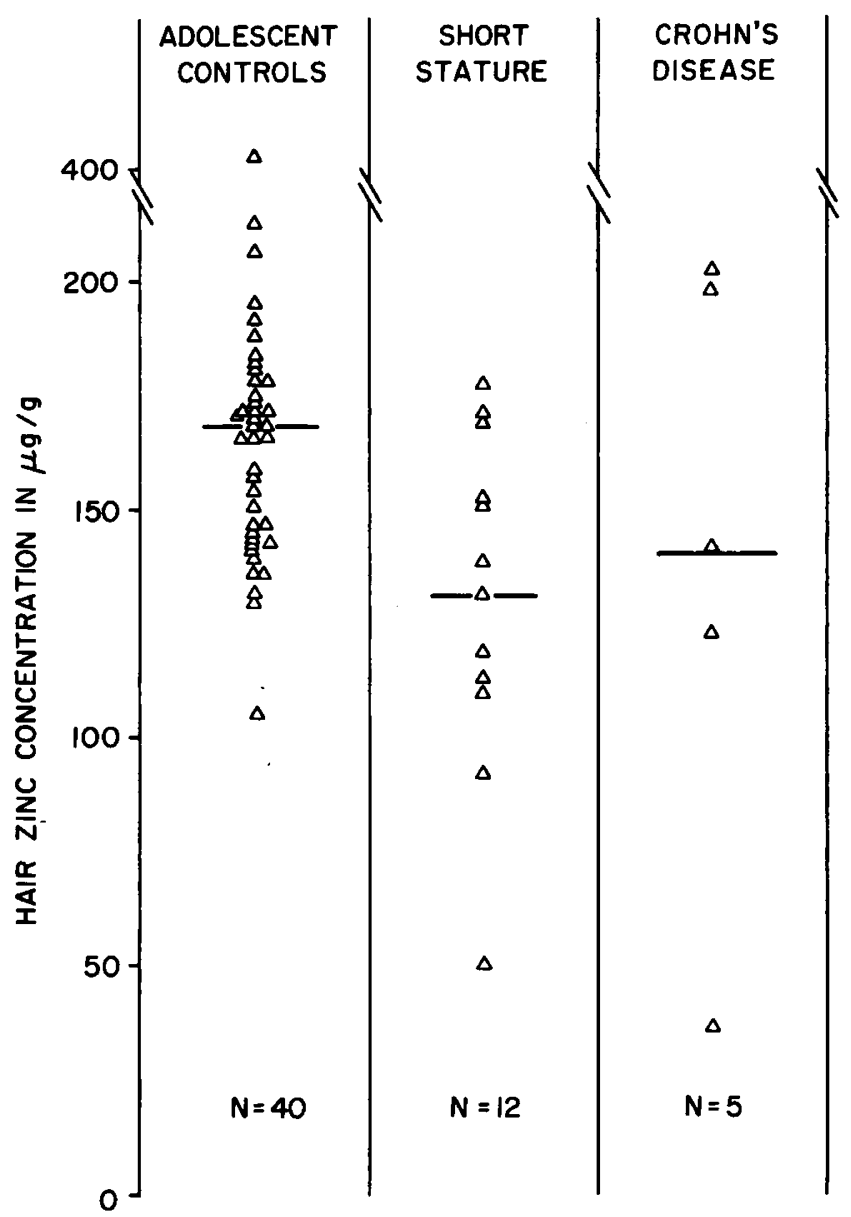

Fig. 2. Hair zinc concentrations in adolescent control subjects, short stature as a variation of normal subjects, and juvenile Crohn's disease patients with growth arrest.

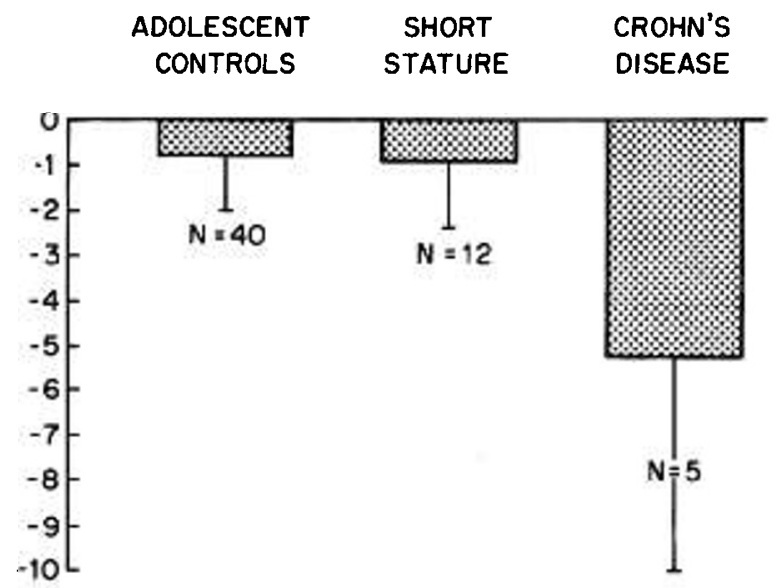

Fig. 3. Taste detection scores in adolescent control subjects, short stature as a variation of normal subjects, and juvenile Crohn's disease patients with growth arrest.

physical examinations, and exclusion of known systemic, endocrinologic, and metabolic causes of short stature. All of the group had a normal linear growth velocity. Linear growth velocity was determined by serial measurement over a 6-month period or longer in all but two in whom such a history could be documented. Growth rates above the 3 rd percentile of the longitudinal velocity standards of Tanner et al. (15) were used as the "normal standard." To resolve the individual differences in growth velocity which were observed because of differences in pubertal status, the 
linear growth rates were assessed in relation to each subject's skeletal age which was determined from radiographs of the left hand by the method of Gruelich and Pyle (2).

Five adolescent patients with Crohn's disease, diagnosed on the basis of clinical and radiologic criteria, who had a plateaued arrest of linear growth with an increase of less than $0.5 \mathrm{~cm}$ during the 6 months before their entering the study were followed in the Gastroenterology Clinic of the University of Chicago Hospitals and Clinics. Four of the five were below the 10th percentile of height and all were prepubertal; the two females had delayed onset of puberty (Table 2 ).

A group of 40 apparently healthy adolescent students, 16 females and 24 males, aged 10-17 years with a mean age of 12 years and 10 months who had been longitudinally examined, served as controls. All of the subjects and their parents agreed to participation in the study after a full explanation of the nature and purpose of the investigation.

Blood samples were taken in mid- to late morning before lunch in all clinic and day school subjects. Venous blood was drawn into plastic syringes and placed in plastic containers that were free of trace metals. The samples were anticoagulated with zinc-free oxalate, and centrifuged for separation of plasma promptly. Hemolyzed samples were discarded. Hair samples were obtained from the occipital scalp with stainless steel scissors. Hair was cut at the skin level, and the proximal $1-2 \mathrm{~cm}$ were analyzed by atomic absorption spectrometry after cutting into sections of about $1 \mathrm{~mm}$, washing in a detergent, and ashing in nitric acid.

The 3-drop forced choice dilution technique $(5,6)$ was used to quantitate taste acuity. Five dilutions of tastant solutions representing salty (sodium chloride), sweet (sucrose), bitter (urea), and sour (hydrochloric acid) were employed. For each dilution, 3 drops were presented in a changing order to alternate sides of the tongue. Two drops contained distilled water and 1 drop contained the tastant. The subject was asked to identify the drop which was not water (taste detection) and to identify its taste correctly (taste recognition). From these data, detection and recognition thresholds for representatives of four taste qualities were determined. For comparison of the groups, a numerical taste detection score was calculated by assigning a -1 for each of the 20 tastant dilutions which could not be correctly distinguished from water.

\section{RESULTS}

\section{CHILDREN WITH SHORT STATURE AS A VARIATION OF NORMAL}

Tabular data for the individual indices of zinc nutrition are shown in Table 1. Plasma zinc data are shown in Figure 1. There was no statistical difference between the mean of $75.3 \pm 10.7 \mu \mathrm{g} / \mathrm{dl}$ for SVN patients and $78.6 \pm 17.7 \mu \mathrm{g} / \mathrm{dl}$ for control subjects, and none of the individual values for plasma zinc for the SNV patients fell below the range observed in the adolescent control group. Figure 2 illustrates hair zinc concentrations. One SVN subject had a hair zinc level below $70 \mu \mathrm{g} / \mathrm{g}$ and one other had a hair zinc level which might be considered borderline. The mean hair zinc of the
SVN patients was significantly below that of the adolescent control subjects, $131 \pm 37 \mu \mathrm{g} / \mathrm{g}$ vs. $168 \pm 44 \mu \mathrm{g} / \mathrm{g}(P<0.02)$. Nevertheless, $88 \%$ of SVN patients had hair zinc values within the normal range.

No difference was found between the mean taste detection score of the patients and the control subjects, $0.9 \pm 1.4$ vs. $0.8 \pm 1.0$ (Fig. 3). Neither of the two patients with deficient hair zinc concenirations had hypogeusia or suspiciously low plasma zinc levels (Table 1), and both had normal growth velocities.

\section{CROHN'S DISEASE AND GROWTH ARREST}

Nutritional data for this group is given in Table 2. The mean plasma zinc concentration, $46.2 \pm 12.6 \mu \mathrm{g} / \mathrm{dl}$, for the five patients with Crohn's disease and growth arrest (Fig. 1) was significantly reduced $(P<0.001)$. Four had plasma zinc values below the range of the adolescent control subjects. A wide scatter in hair zinc concentrations was found; only one patient had two values below $70 \mu \mathrm{g} / \mathrm{g}$ (Fig. 2). The mean taste detection score $(-5.2 \pm 4.8)$ of these patients was significantly $(P<0.001)$ below that $(-0.8 \pm$ 1.0) for the control subjects (Fig. 3), and four had objective hypogeusia. Detailed detection and recognition thresholds for all subject groups are given in the Appendix.

\section{DISCUSSION}

\section{LOW HAIR ZINC, ANOREXIA, POOR GROWTH, AND HYPOGEUSIA}

Zinc responsive growth failure in adolescents has been well documented from Egypt $(7)$ and Iran $(3,9)$. In addition, it is possible that zinc deficiency may contribute to the growth retardation of children with cystic fibrosis (4) and sickle cell disease (1). One purpose of the present study was to learn whether there is a substantial incidence of a reported zinc deficiency syndrome (5) among children evaluated for growth retardation. Of the $12 \mathrm{SVN}$ patients one was found to have a hair zinc concentration below $70 \mu \mathrm{g} / \mathrm{g}$, one had a hair zinc in the borderline range, and none had hypogeusia. Thus, in no individual was the constellation of findings described by Hambidge et al. (5) found.

\section{TASTE ACUITY}

The findings for taste acuity were similar to those of Hambidge et al. (5) in Denver in our adolescent control group and SVN subjects. Hambidge et al. (5) found that 11 control children could detect the lowest dilution of all four tastants and recognize the second lowest dilution. The 40 adolescent control subjects in our study detected the most dilute solution in 129 of 160 tests $(81 \%)$ and recognized the second most dilute solution in 143 of 160 tests $(89 \%)$. The 12 SVN subjects detected the first strength solution $83 \%$ of the time and identified the second strength solution $85 \%$ of the time. Four of the five CD patients displayed hypogeusia similar to that found in the growth-retarded patients with low hair zinc reported by Hambidge et al. (5).

Table 2. Profile of patients with juvenile Crohn's disease

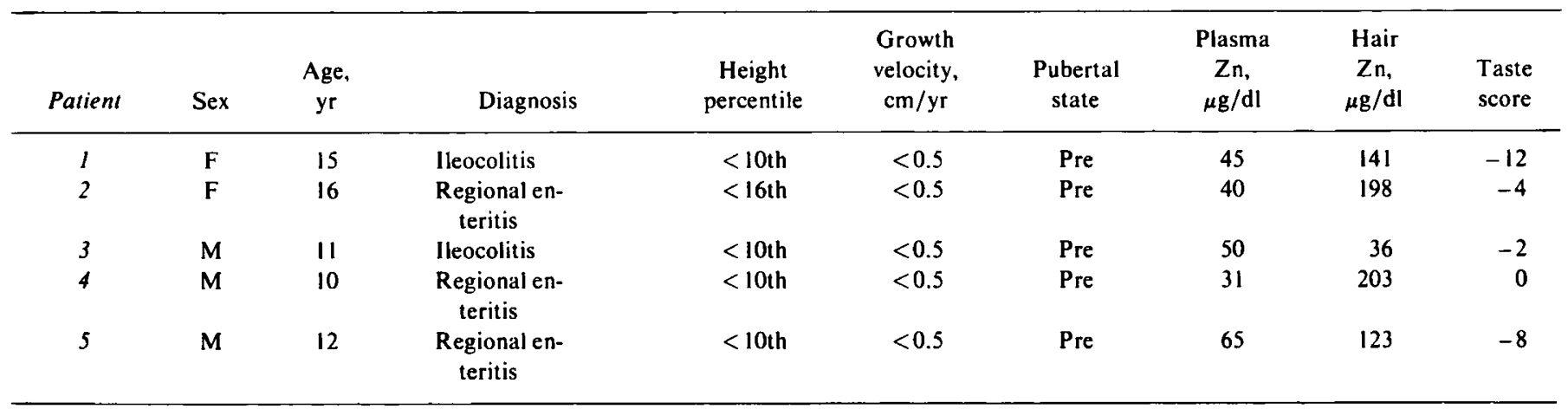




\section{ZINC NUTRITION AND GROWTH DYNAMICS}

The state of the art in our understanding of human zinc nutrition is such that several indices of zinc status, including plasma or serum zinc, erythrocyte zinc, hair zinc, urinary zinc, salivary zinc, and taste acuity, have all been used in the evaluation of zinc nutriture (12). In addition to measurements of hair zinc and taste acuity used by Hambidge et al. (5), plasma zinc was used in the present study. Together these indices have been used to provide a measurement of zinc status. A second focus of this study was the relationship of zinc nutrition to linear growth. In contrast to the normal growth patterns of the SVN patients in whom retrospective documentation was available, all patients with $C D$ demonstrated a plateau of growth. Moreover, the five patients with CD and growth arrest showed multiple evidences of impaired zinc nutrition. Plasma zinc concentrations were low in four of five patients, hypogeusia was present in four, and hair zinc was abnormal in one patient. These observations, coupled with previous findings in zinc-deficient Egyptian adolescents (11) and in zinc-deficient experimental animals (16), are consistent with the interpretation that a pattern of growth retardation that follows a normal velocity is not likely to be due to zinc deficiency. If this interpretation of the data is correct, it can be suggested that a history of a normal linear growth velocity tends to rule out zinc deficiency as a probable cause of the delayed growth. On the other hand, in children and adolescents who display a plateau in growth, zinc deficiency must be entertained as a possible cause.

\section{SUMMARY}

The zinc nutriture of 12 children with a delay in growth but a normal linear growth rate and of 5 juvenile Crohn's disease patients with growth arrest was assessed. The former group did not demonstrate a constellation of findings consistent with zinc deficiency whereas the latter group did. We conclude that a normal pattern of growth is consistent with normal zinc nutrition but that a plateau in growth is observed when zinc deficiency is present.

\section{REFERENCES AND NOTES}

1. Brewer, G. J., Prasad, A. S., Oelshlegl, F. J., Jr., Schoomaker, E. B., Ortega, J., and Oberleas, D.: In: A. S. Prasad: Trace Elements in Human Health and Disease, pp. 283-294 (Academic Press, New York, 1976).

2. Gruelich, W. W., and Pyle, S. I.: Radiographic Atlas of Skeletal Development of the Hand and Wrist, Ed. 2 (Stanford University Press, Palo Alto, Calif., 1959).

3. Halsted, J. A., Ronaghy, H. A., Abadi, P., Haghshenass, M., Amirhakemi, G H., Baraket, R. M., and Reinhold, J. G.: Zinc deficiency in man: The Shiraz experiment. Amer. J. Med., 53: 277 (1972).

4. Halsted, J. A., and Smith, J. C.: Plasma-zinc in health and disease. Lancet, $i: 322$ (1970).

5. Hambidge, K. M. Hambidge, C., Jacobs, M., and Baum, J. D.: Low levels of zinc in hair, anorexia, poor growth and hypogeusia in children. Pediat. Res., 6 : 88 (1972).

6. Henkin, R. I., Schechter, P. J., Hoye, R., and Mattern, C. F. T.: Idiopathic hypogeuisa with dysgeusia, hyposmia and dysosmia. A new syndrome. $J$ Amer. Med. Ass. 217: 434 (1971)

7. Prasad, A. S., Miale, A., Farid, Z., Sandstead, H. H., and Schulert, A. R. Zinc metabolism in patients with the syndrome of iron deficiency anemia, hepatosplenomegaly, dwarfism, and hypogonadism. J. Lab. Clin. Med., 61: 537 (1963).

8. Reinhold, J. G., Faradji, B., Abadi, P., and Ismail-Beigi, F.: Binding of zinc to fiber and other solids of whole wheat bread. In: A. S. Prasad: Trace Elements in Human Health and Disease, pp. 163-180 (Academic Press, New York, 1976).

9. Ronaghy, H.S., Reinhold, J. G., Mallouidi, M., Ghavani, R., Spirey-Fox, M. R. and Halsted, J. A.: Zinc supplementation of malnourished school boys in Iran Increased growth and other effects. Amer. J. Clin. Nutr., 27: 112 (1974).

10. Sandstead, H. H.: Some trace elements which are essential for human nutrition: Zinc, copper, manganese and chromium. Prog. Food Nutr. Sci., 1: 371 (1975).

11. Sandstead, H. H., Prasad, A. S., Shulert, A. R., Farid, A., Miale, A., Bassilly, S., and Darby, W. J.: Human zinc deficiency. Endocrine manifestations and response to treatment. Amer. J. Clin. Nutr., 20: 422 (1967).

12. Sandstead, H. H., Vo-Khactu, K. P., and Solomons, N. W.: Conditioned zinc deficiencies. In: A. S. Prasad: Trace Elements in Human Health and Disease, pp. 33-50 (Academic Press, New York, 1976).

13. Schechter, P. J., Friedewald, W. T., Bronzert, D. A., Raff, M. S., and Henkin, R I.: Idiopathic hypogeusia. A description of the syndrome and a single blind study with zinc sulfate. In: C. C. Pfeiffer: International Review of Neurobiology, Supplement 1, pp. 125 (Academic Press, New York, 1972).

14. Solomons, N. W., Vo-Khactu, K. P., Sandstead, H. H., and Rosenberg, 1. H. Zinc nutrition in Crohn's disease [Abstract]. Clin. Res., 2l: No. 3, April (1974).
15. Tanner, J. M., Whitehouse, R. H., and Takaishi, M.: Standards from birth to maturity for height, weight, height veolcity and weight velocity: British children, 1965, Part II. Arch. Dis. Childhood, 41: 613 (1966).

16. Underwood, E. J.: Trace Elements in Human and Animal Nutrition, Ed. 3, p. 222 (Academic Press, New York, 1971).

17. Wilkins, L.: The Diagnosis and Treatment of Endocrine Disorders in Childhood and Adolescence, Ed. 3 (Charles C Thomas, Springfield, III., 1965).

18. The authors are grateful to Dr. Kim Vo-Khactu for her work on the biochemical determinations, to Ms. Ann Eggleton for her assistance with the adolescent control studies, and to Ms. Kathy Linneman for her assistance in preparation of the manuscript.

19. The project was supported in part by a grant from the Gastrointestinal Research Foundation. Dr. Solomons is the recipient of the Josiah Macy Jr. Foundation Faculty Fellows Award and the Nutrition Foundation Future Leader's Award. 20. Requests for reprints should be addressed to: H. H. Sandstead, M.D., P. O. Box 7166, University Station, Grand Forks, North Dakota, 58201

21. Accepted for publication May 21, 1976.

\section{APPENDIX}

Tastant concentrations in millimoles were: $\mathrm{NaCl}, 30-60-90-150$ 300; sucrose, 15-30-60-150-300; urea, 120-150-300-500-1000; and $\mathrm{HCl}, 15-30-60$. Data are presented in Tables 1-3 of the Appendix with detection threshold to the left of the slash, and recognition threshold to the right.

Table 1. Taste thresholds in adolescent controls

\begin{tabular}{|c|c|c|c|c|}
\hline Patient & $\mathrm{NaCl}$ & Sucrose & Urea & $\mathrm{HCl}$ \\
\hline 1 & $30 / 30$ & $15 / 15$ & $120 / 120$ & $6 / 6$ \\
\hline 2 & $30 / 60$ & $15 / 15$ & $120 / 120$ & $6 / 6$ \\
\hline 3 & $30 / 30$ & $15 / 30$ & $120 / 150$ & $15 / 30$ \\
\hline 4 & $30 / 60$ & $15 / 15$ & $120 / 150$ & $6 / 30$ \\
\hline 5 & $30 / 30$ & $15 / 30$ & $120 / 120$ & $6 / 6$ \\
\hline 6 & $30 / 30$ & $15 / 15$ & $120 / 120$ & $3 / 3$ \\
\hline 7 & $30 / 60$ & $15 / 15$ & $120 / 150$ & $3 / 15$ \\
\hline 8 & $30 / 30$ & $15 / 15$ & $120 / 120$ & $3 / 3$ \\
\hline 9 & $30 / 30$ & $15 / 15$ & $120 / 120$ & $6 / 6$ \\
\hline 10 & $30 / 30$ & $15 / 15$ & $150 / 150$ & $30 / 30$ \\
\hline 11 & $30 / 30$ & $15 / 15$ & $120 / 300$ & $15 / 15$ \\
\hline 12 & $30 / 30$ & $15 / 15$ & $120 / 120$ & $15 / 15$ \\
\hline 13 & $30 / 30$ & $15 / 15$ & $120 / 150$ & $3 / 3$ \\
\hline 14 & $30 / 30$ & $15 / 15$ & $150 / 150$ & $3 / 3$ \\
\hline 15 & $30 / 60$ & $15 / 15$ & $150 / 150$ & $3 / 3$ \\
\hline 16 & $30 / 30$ & $15 / 15$ & $120 / 120$ & $3 / 15$ \\
\hline 17 & $30 / 60$ & $15 / 15$ & $120 / 150$ & $3 / 15$ \\
\hline 18 & $30 / 30$ & $15 / 15$ & $120 / 120$ & $3 / 3$ \\
\hline 19 & $30 / 30$ & $15 / 15$ & $120 / 120$ & $3 / 3$ \\
\hline 20 & $30 / 30$ & $15 / 15$ & $120 / 120$ & $3 / 3$ \\
\hline 21 & $30 / 30$ & $15 / 15$ & $120 / 120$ & $3 / 3$ \\
\hline 22 & $30 / 60$ & $15 / 30$ & $120 / 120$ & $3 / 3$ \\
\hline 23 & $30 / 30$ & $15 / 15$ & $120 / 120$ & $3 / 3$ \\
\hline 24 & $30 / 30$ & $15 / 15$ & $120 / 150$ & $3 / 15$ \\
\hline 25 & $30 / 30$ & $30 / 30$ & $120 / 120$ & $3 / 6$ \\
\hline 26 & $30 / 30$ & $30 / 30$ & $120 / 150$ & $6 / 30$ \\
\hline 27 & $30 / 30$ & $30 / 30$ & $120 / 150$ & $6 / 6$ \\
\hline 28 & $30 / 30$ & $30 / 30$ & $120 / 120$ & $15 / 30$ \\
\hline 29 & $30 / 30$ & $30 / 30$ & $150 / 150$ & $15 / N^{1}$ \\
\hline 30 & $30 / 30$ & $30 / 30$ & $150 / 150$ & $15 / 30$ \\
\hline 31 & $30 / 30$ & $30 / 30$ & $120 / 120$ & $3 / 3$ \\
\hline 32 & $30 / 30$ & $30 / 30$ & $120 / 120$ & $3 / 3$ \\
\hline 33 & $30 / 30$ & $30 / 30$ & $120 / 120$ & $3 / 6$ \\
\hline 34 & $30 / 30$ & $15 / 15$ & $120 / 120$ & $6 / 15$ \\
\hline 35 & $30 / 30$ & $15 / 15$ & $120 / 120$ & $3 / 3$ \\
\hline 36 & $30 / 30$ & $15 / 15$ & $120 / 120$ & $3 / 6$ \\
\hline 37 & $30 / 30$ & $15 / 15$ & $120 / 150$ & $3 / 3$ \\
\hline 38 & $30 / 30$ & $15 / 15$ & $120 / 150$ & $3 / 15$ \\
\hline 39 & $30 / 30$ & $15 / 30$ & $150 / 150$ & $3 / 3$ \\
\hline 40 & $30 / 30$ & $15 / 15$ & $120 / 120$ & $15 / 30$ \\
\hline
\end{tabular}

${ }^{1}$ NR: not recognized. 
Table 2. Taste thresholds in short stature as a variant of normal

\begin{tabular}{ccccc}
\hline Patient & $\mathrm{NaCl}$ & Sucrose & Urea & $\mathrm{HCl}$ \\
\hline$I$ & $30 / 30$ & $15 / 30$ & $150 / 150$ & $6 / 30$ \\
2 & $30 / 30$ & $15 / 15$ & $120 / 120$ & $6 / 6$ \\
3 & $30 / 30$ & $15 / 60$ & $120 / 150$ & $6 / 6$ \\
4 & $30 / 30$ & $15 / 30$ & $120 / 120$ & $3 / 3$ \\
5 & $30 / 30$ & $15 / 15$ & $120 / 150$ & $3 / 6$ \\
6 & $30 / 30$ & $15 / 15$ & $120 / 120$ & $6 / 30$ \\
7 & $30 / 30$ & $15 / 15$ & $120 / 120$ & $3 / 3$ \\
8 & $30 / 60$ & $15 / 30$ & $120 / 120$ & $6 / 30$ \\
9 & $30 / 30$ & $15 / 15$ & $120 / 120$ & $3 / 3$ \\
10 & $60 / 60$ & $15 / 15$ & $150 / 150$ & $30 / 60$ \\
11 & $30 / 30$ & $15 / 15$ & $120 / 150$ & $3 / 30$ \\
12 & $30 / 30$ & $15 / 30$ & $120 / 120$ & $3 / 15$ \\
\hline
\end{tabular}

Copyright @ 1976 International Pediatric Research Foundation, Inc.
Table 3. Taste thresholds in juvenile Crohn's disease

\begin{tabular}{ccccc}
\hline Patient & $\mathrm{NaCl}$ & Sucrose & Urea & HCl \\
\hline 1 & $150 / 150$ & $30 / 30$ & $500 / 1,000$ & ND/NR $^{1}$ \\
2 & $90 / 90$ & $15 / 30$ & $150 / 150$ & $6 / 6$ \\
3 & $30 / 60$ & $15 / 30$ & $150 / 150$ & $6 / \mathrm{NR}$ \\
4 & $30 / 60$ & $15 / 15$ & $120 / 150$ & $3 / 3$ \\
5 & $60 / 90$ & $60 / 150$ & $150 / 300$ & $60 / 60$ \\
\hline
\end{tabular}

${ }^{1}$ ND: not detected; NR: not recognized.
Atherosclerosis

cholesteryl ester storage disease

lysosomal acid lipase

\title{
Genetic Variation of Lysosomal Acid Lipase
}

\author{
J. A. CORTNER, ${ }^{(50)}$ P. M. COATES, E. SWOBODA, AND J. D. SCHNATZ \\ Departments of Pediatrics and Medicine, State University of New York at Buffalo and Children's Hospital of \\ Buffalo, Buffalo, New York; Department of Pediatrics, University of Pennsylvania and Children's Hospital of Philadelphia, \\ Philadelphia, Pennsylvania, USA
}

\section{Extract}

Lysosomal acid lipase (LAL) activity was measured using a new fluorometric assay in cultured skin fibroblasts from eight control subjects, two obligate heterozygotes for Wolman's disease (WD), one patient with WD, and one patient with cholesteryl ester storage disease (CESD). The LAL activities (mean \pm SD) were $25.8 \pm 8.2$, $13.2 \pm 0.1,1.1$, and $1.4 \mathrm{nmol}$ 4-methylumbelliferyl oleate (4-MUO) hydrolyzed $/ \mathrm{min} / \mathrm{mg}$ protein, respectively. These results compare favorably with those obtained using standard radioassays. The LAL activities of two cultures of amniotic fluid cells were 12.1 and 10.5. The LAL activity (mean \pm SD) of peripheral leukocytes obtained from 34 laboratory volunteers ( 19 females, 15 males) was $4.0 \pm 1.8$. Partially purified lymphocytes contained about 25 times as much LAL activity as did granulocytes. Cellogel electrophoresis, followed by staining with 4-MUO, showed at least two bands of LAL ( $A$ and B) from normal fibroblasts, amniotic fluid cells, and lymphocytes. Band A was absent from WD and CESD fibroblasts and was reduced in fibroblasts of the WD heterozygotes.

\section{Speculation}

Deficiency of lysosomal acid lipase activity is associated with lysosomal accumulation of cholesteryl esters and triglycerides. One of the early events in atherogenesis is the accumulation of cholesteryl esters in the lysosomes of arterial smooth muscle cells. Genetic variants of lysosomal acid lipase, resulting in reduced activity or altered catalytic properties, may be predisposing factors in the development of premature atherosclerosis.
Deficiency of lysosomal acid lipase (LAL) (33) is associated with a wide spectrum of clinical disease in man, ranging from the fatal infantile form of Wolman's disease (WD) to the relatively benign disorder, cholesteryl ester storage disease (CESD). There have been some 35 cases of WD, its clinical variants, and CESD reported in the literature since $1956(19,25)$. Table 1 summarizes the cases from 1971 to the present. Deficiency of LAL in these diseases results in massive lysosomal accumulation of neutral fats, chiefly cholesteryl esters and triglycerides, in the cells of a variety of tissues (9). The acute infantile form of WD is usually fatal within 6 months of life. Variants of WD with later onset and longer survival have been reported (19). Other variants of WD, as well as CESD, are apparently clinically benign conditions. The reported patients are still alive, with the exception of female twins (10) who died of unrelated causes.

In this report, we present an additional case of WD with details of procedures for the quantitative assay and electrophoresis of LAL in fibroblasts of this patient, her parents, and a patient with CESD.

\section{CASE REPORT}

$A J$ was an apparently normal newborn girl delivered uneventfully to a healthy gravida 1 , para 0,20 -year-old Caucasian woman and her 26-year-old unrelated Caucasian husband. The family history was unremarkable. The patient was well until 8 weeks of age when abdominal distention was noted. She continued to appear alert and well except for increasing abdominal distention until her first hospital admission (October 28, 1971) at 10 weeks of age. On 